\title{
Design Recommendations for Web-based Career Guidance Platforms - Let Young Women Experience IT Careers!
}

\author{
Ute Paukstadt \\ University of Münster \\ ute.paukstadt@ercis.uni- \\ muenster.de \\ Valerie Dahl \\ University of Münster \\ v.dahl@uni-muenster.de
}

\author{
Katrin Bergener \\ University of Münster \\ katrin.bergener@ercis.uni- \\ muenster.de \\ Cornelia Denz \\ University of Münster \\ denz@uni-muenster.de
}

\author{
Jörg Becker \\ University of Münster \\ joerg.becker@ercis.uni- \\ muenster.de \\ Inga Zeisberg \\ University of Münster \\ zeisberg@uni-muenster.de
}

\begin{abstract}
Despite a variety of intervention programs in the western society over the last decades, still too few young women are interested in an information technology (IT) career.

While looking for career information and guidance, young women consult family and friends but also the internet. Although there is already a plethora of career information websites, those are seldom tailored to the interests of young women.

To address the IT-gender gap with the design of a platform that appeals to the needs of the target group, we firstly analyzed existing German websites for career information and guidance. The analysis was framed by literature on women's IT career choice barriers. Secondly, we evaluated selected websites with focus groups of female students. Finally, we present design recommendations to enhance web-based career information and guidance platforms for young women to raise their interest in IT-related careers.
\end{abstract}

\section{Introduction}

Although various programs in Western and European Countries have been established for more gender equality in the IT workforce, there is still a lack of female IT specialists and IT students [42].

For Germany, as the exemplary country for our study, current statistics show an uptake of women beginning to study an IT-related subject (24,6\%: 16.947 female freshmen in 2015) [37]. However, in the IT departments of many companies, less than one out of 10 employees is female [40]. Due to the ongoing digitization in professional and private life, the demand for IT specialists will rise even further [10], so naturally, 25\% women studying technology studies is far too less [40, 43]. Another economic reason for a high diversity in IT is the potential and the perspective female IT specialists bring to IT and this is currently ignored by the IT industry [1]. Thus, there are enough reasons to look into the career choice process of young women and the possibilities to raise their interest in IT careers.

Most of the programs and interventions aim to address this issue with "offline" projects taking place in formal settings e.g. special computing courses for girls, summer schools, girl`s clubs for computing, or girl's days where young women can get in touch with IT [16, 20, 30, 49]. Additionally, research has implemented games, simulations, and other software for introducing young women in classroom settings to computing, which is, however, mostly limited to coding $[33,49]$. This research often deals with interest and skill development in IT in general [26, 29]. It does not necessarily include providing an understanding of specific IT job profiles such as, e.g., the job of a datascientist, IT security specialist, or a database administrator.

Further on, there are few studies dealing with informal, self-directed and out-of-classroom activities to excite young women for IT careers through other means, e.g. with the help of web-based career guidance systems (see literature review in section 3 ).

The question exists whether (yet another) web platform is the right enabler and empowering tool for career orientation for you women. Still, we argue that it is fruitful to look at web-based career guidance. On the one hand, the internet is omnipresent among the young generation and many students look for career information on the World Wide Web. On the other hand, studies [31] show a dissatisfaction of students with current web-based career information offerings in Germany. Moreover, a recently published study of 
Microsoft [39] demands for more opportunities for getting in touch with computer science in and out of the classroom like Hour of Code to encourage young women for IT.

We therefore focus on web-based career guidance for tackling the gender-gap problem among the IT workforce.

Hence, our research is guided by the following question: How can we improve career guidance websites to the needs of young women and evoke their interest for IT careers?

To answer this question, we used literature reviews, website analysis as well as qualitative research.

The female underrepresentation in the IT workforce underlies several causes. The career choice barriers stated in the literature as well as the state-of-the-art research on Computer-Assisted Career Guidance Systems forms our starting point (sections 2 and 3).

We used the findings as a basis for our following analysis of career guidance websites in section 4 . We analyzed more than 100 career information and guidance websites in German language and compared empirically observable elements of the websites. We identified six websites with specific dominant elements and presented those websites to different focus groups for evaluation (section 5). Combining the findings on current literature, the website analysis, and the focus groups we were able to derive design recommendations for improving career guidance websites especially in terms of encouraging young women's interest in IT careers (section 6). Based on the design recommendations, we propose a new system type, the "Computer-Assisted Career Guidance and Experience System”. Subsequently, we draw conclusions, mention the limitations, and reflect our results (section 7).

\section{Young women's IT career choice barriers}

A lot of research deals with the causes for the underrepresentation of women in STEM. We found several theoretical frameworks on young women's career choice barriers and studies describing the influence factors of career choice behavior, e.g. see [1, 17, 18, 38]. Comparing the career choice models and further literature it can be stated that the influence of aptitude on the career choice is moderated and framed by many environmental factors. For instance, the career choice model of Dick and Rallis (1991) describes the impact of skills, experiences, socialization factors and cultural milieu on the selfconcept and career-related values (including interest, abilities and motivation) and, thus, on career choice. This model as well as further studies on young women's career choice provide the theoretical framework for our research by giving insights on how to address young women in terms of IT-related careers.

Figure 1 summarizes the influencing factors identified in literature that are assumed to be relevant in terms of a web-based approach.

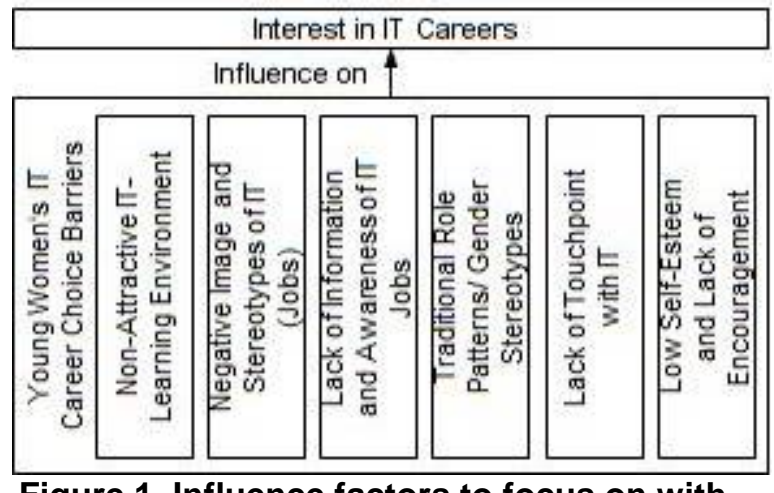

Figure 1. Influence factors to focus on with a web-based approach

As our research aims to improve web-based interventions, we did not look at social influences like parents, school, and social environment. Below, we give further explanation to those career choice barriers and implications on how to address them.

\section{- Non-Attractive IT-Learning Environments}

Several authors note that the learning environment for IT topics is not welcoming or attractive to young women [6, 30]. For example, computing is taught male- oriented in school and perceived as a masculine field [15].

To address this barrier, authors recommend to tailor IT topics to young women's interests [20]: young women are interested in group work and communication [6, 7, 19], meaningful and valueoriented tasks (e.g. social and environmental issues), and prefer practical problem solving. Also, a gendersensitive language and presentation could be fruitful [46]. Young women could further be attracted by presenting more business-oriented IT careers, as those require other skills than traditional IT careers like computer scientists (e.g. higher communication and social skills) [7].

\section{- Negative Image and Stereotypes of IT (Jobs)}

Young women often consider IT as abstract, theoretical and boring $[4,13]$. Images of stereotypical male IT "geeks", working alone many hours in front of a computer are rather discouraging to young women $[6$, $11,30]$.

Thus, image-changing campaigns of IT (careers) are needed, so that young women perceive that working in IT can be very diverse, and work content can range from creative to communicative tasks and meaningful aspects like helping to improve the world, e.g. in Green-IT [7]. 
- Lack of Information and Awareness of IT Jobs

Many (female) students are ignorant of occupational options, tasks and requirement of IT jobs $[11,12,36]$. Young women are not aware how exciting IT jobs can be $[16,36]$. Therefore, it is necessary to increase and improve the information base to young women, e.g. in interactive ways and not only based on functional information [16, 20]. Literature also recommends to link each degree program with specific career tracks, that indicate which kind of knowledge and skills is needed for a specific career specialization [11]. In addition, it could be helpful to address common fears related to IT jobs honestly, e.g. fear of outsourcing, job-loss, and working conditions (family planning) [7].

- Traditional Role Patterns/ Gender Stereotypes

The gender role socialization leads to gender differences in interests and career choice [19]. Parents, peers, media, and school (unconsciously) promote gender stereotypes, e.g. "Tech is for boys" [15]. Consequently, women prefer jobs that help others and support family plans, favor humanities, arts and education majors. Men prefer working with physical objects, abstract concepts, favor math and physical majors, and are income focused [19].

\section{- Lack of Touchpoint with IT}

Young women reduce their use of IT to a narrow range of possibilities, primarily communication purposes [20].

For this reason young women should be provided with more practical experience [20]. Research [5, 9] suggests to use games and virtual simulations for career exploration and to enhance skill development that can be gained through interactive ways of exploring virtual worlds and constructive learning exercises.

In addition, young women should be shown the practical use of end-products, e.g. use of business software in specific industries like financial services, health-care, law enforcement, and others instead of just presenting singular technology components [7].

\section{- Low Self-Esteem in IT Skills and Lack of Encouragement}

Female students often have low self-esteem in terms of computing skills [41]. Therefore, young women need external stimulation and encouragement, for example in form of visible and authentic role models [2, 6, 8, 36]. They can be further encouraged by being asked for preferences in terms of considerations and aspects instead of occupational titles (e.g. "What activities do you enjoy?”) [22].

In general, research shows that interventions have to start at an early age, for example before high school, as career choice barriers are already set in lower secondary school [17].

\section{Computer-Assisted Career Guidance Systems}

As we reviewed scientific literature on the topic, we found that there is no clear definition for information systems that offer information for young people during their career choice process. Instead, many similar expressions and synonyms are used (see $[24,25,44])$. The most common term, however, is "Computer-Assisted Career Guidance Systems" (CACGS) [14, 21, 44]. Thus, we decided to use this term as well.

CACGS can be defined as an interactive guidance application used by an individual person independently to retrieve useful information for self-assessment and career exploration and choice [21].

A lot of CACGS are based upon the process of career decision-making as (for example) described by the PIC model [23]. The model consists of three stages - (1) prescreening, (2) in-depth exploration, and (3) choice - and describes how to narrow down a countless number of career options with self-assessment and exploring career information to a manageable number of careers and finally identifying the most suitable alternative.

Despite the fact that career guidance being a lifelong procedure, we will mainly focus on the first career choice decision, where a student clarifies and identifies options, and implements a decision as well as adapts the decision [3].

Typical core elements of CACGS are career assessments (e.g. testing interests, skills, values and employment preferences to promote the user's selfimage) and databases that deliver data sets to different occupations, majors, and colleges. In terms of the career assessments, many systems use a "matchingalgorithm" that is more or less sophisticated and reveals a list of (hopefully) good-fitting occupations or related occupations that could also be relevant [14].

Besides comprehensive systems consisting of multiple tools and elements to support the career choice process, there are also websites only offering specific career guidance services like assessments ("self-directed search")[21].

Nowadays most CACGS are presented in a webbased version like the Occupational Outlook Handbook (bls.gov/oco) and O*NET systems [34]. Some authors $[25,44]$ call this new generation "Internet-based Career Guidance Systems". The technology progress with social web, mobile apps, and games opens up new possibilities for the field of carrier guidance [45]. Nevertheless, so far, despite a vast amount of career- 
related websites [25], very little research has been conducted in the field of Information Systems so far.

\section{CACGS analysis}

\subsection{Method for CACGS analysis}

The literature review on CACGS marks the starting point of the website analysis as we also searched for possible existing categorizations of CACGS. Besides the characteristics of CACGS, already presented in section 3, we found few attempts to categorize those type of information system in general e.g. [27, 32, 35]. For our research none of these categorizations seem to be appropriate. They are either outdated, have a more holistic view on career counseling or a different understanding of CACGS (only fee-based and log-in and/ or focused on diagnostic assessment). Moreover, we could not find a systematic categorization of this genre that also included modern elements, e.g. gamification and social web.

In our research, we tried to be open for a broad range of career guidance websites, ranging from mainly content-based sites to virtual world approaches. Our research is embedded in an ongoing research project in Germany. Thus, we chose websites in German language as our field of study. Although our main attention was directed to the display of (IT) careers, we also included career guidance websites concentrating on vocational training and majors to get a comprehensive overview on web-based career guidance platforms. As our research is based on freely available websites because they have the widest reach, we also restricted our search area by excluding feebased websites. Further, we did not consider websites that mainly linked to other career guidance websites, as well as corporate career websites, job portals with focus on vacancies, and those websites that only displayed careers as one small subcategory.

To start, we collected career information websites with a Google search. Since it is likely that people only look into the first pages of their search results, we agreed on looking at the first five pages of the Google results. Before starting the search process, we created a keyword list. Searching took place in two phases, first as a rough preliminary search to get indications for targeted search terms and then as a detailed and systematic search. We also added websites that were linked on other meta-websites.

\subsection{Results of the CACGS analysis}

We found about 100 web-based platforms for career information, orientation, and exploration in
German language. Although our search was restricted to German websites, we also had a look at some English websites to get a deeper understanding of the different types of information systems and to eventually be able to see different developments (e.g. gamification).

While analyzing and discussing the results, we defined the category career website elements. The category contains web elements that seem to be relevant for supporting career choice, as they are often implemented on the websites or because of our indications from literature. Those are online tests, videos, mini games, account, (text-based) information, virtual world, social media, and vacancies.

The website element online test can be very diverse from aptitude tests to interests and value tests, and hence, support the user to narrow down the career options. Online tests often are a basic element of career guidance websites, as almost every website offers at least one. We found one or two examples e.g. the website "entdecker.biz-medien.de" that only consist of a test as their only career guidance service. The tests vary widely in their complexity and their scientific level. Several tests, labeled as aptitude tests, interest test, orientation test, or self-assessment consist only of 10-15 questions with a Likert scale. After completing the test, career suggestions are subsequently presented. However, there is often no transparency for the user on how the test generates its results. Most of the German websites do not offer information on the background of their tests, i.e. if their tests rely on scientifically proofed insights or how they were built to deliver reliable results.

Another career website element is social media including features to share information with others, for example via Facebook, Twitter, or a blog. It can also supply a forum and chat for communication with other users. Some platforms like "aubi-plus.de" provide some special features like a 24h WhatsApp career guidance service or a blog.

The website element videos usually depicts people working in the particular careers and/or interviews with people talking about their jobs. For this attribute, we found, for instance, "watchado.com" and "berufe.tv", which are in fact pure video-based platforms as they basically solely provide videos of career depictions.

Furthermore, we defined virtual world as a website element, even though, normally a virtual world is not one unique element but rather a holistic environment of a website that strongly determines all other elements. A virtual world typically plays in a simulated $2 \mathrm{D}$ or $3 \mathrm{D}$ environment, where the user dives into a role and is often able to move around in a virtual setting, for example a company. The user has to interact with 
objects like people in an office to solve realistic business tasks in form of games. As one of many career website elements, a virtual world could only be an additional option to explore career more interactively, besides traditional textual database entries. Websites using the website element virtual world can rarely be found since most of the virtual worlds mentioned in articles were offline or not publicly accessible. One example we also presented to the focus groups is "Serena.thegoodevil.com", which is a fictional comic world for young women to explore green careers and is designed within a current research project.

The element mini games can simulate typical job tasks or consists of little interactive simulations and games like riddles and quizzes. Our analysis also showed that there are only a few gamified platforms that include imbedded games and experience-oriented elements, like the programming games on "hourofcode.com". One example we found was "ausbildung-me.de", which also provides some gamified exercises and aims at young students exploring vocational training options.

Most of the websites we found are mainly information portals relying on text-based information about careers as a core element like "Berufenet", the official website of the German Federal Employment Agency, or "O*Net" in the US. Their data sets often consist of up to hundreds of job profiles in different fields and cover diverse aspects: summary description of the job, job tasks and typical activities, required skills (e.g. critical thinking), work context (e.g. spend time sitting), education requirement (e.g. bachelor's degree), interests (e.g. preference to analytical work), work values, work style (e.g. attention to detail), wages and employment trends, related occupations and typical occupational areas. Thus, we also considered the element (text-based) information as a dominant element of career guidance websites.

Compared to general comprehensive career guidance websites that try to offer data sets for (almost) all jobs, there are also websites focusing on a special target audience like students or graduates, disabled people, or women. These regularly display only a handful of careers or are even specialized on only one job, e.g. "be-optician.de” for opticians, "gotextile.de" for careers in the textile industry or "itberufe.de" for IT careers. In most cases, young women as target group are if at all addressed on special subpages to present traditionally "masculine” jobs. In terms of IT careers, we found just one website in Germany, namely "it-berufe.de”, which deals with vocational training options in the IT field, addressing both, young men and women.
Another website element, especially comprehensive career guidance websites frequently offer, are vacancies of companies.

In some cases users also have the option or the obligation to create an account - and if necessary- an avatar. For example, the account on "aubi-plus.de" offers the chance to create a search agent and to save vacancies. The website "whatchado.com" uses account data to make better recommendations on jobs.

Most of the career guidance websites offer a balanced set of content types and web elements particularly text-based information, eventually supported by videos, online tests, and social media functions. Some platforms even offer further services like course finder tools or specific sections for job training applications. The menu of the career guidance websites is normally organized according to the career choice process: one would first do a self-assessment to explore one`s skills, interests and values, then explore possible jobs, and finally decide and apply for jobs.

The division of career guidance websites into their typical career website elements gave us the opportunity to pick one good example of every dominant or special website feature. This was necessary for the preparation of the focus group study in order to find out, which elements are appealing to young women.

\section{CACGS focus group evaluation}

\subsection{Focus group method}

In order to explore and analyze young women's preferences regarding CACGS, we organized focus groups with participants from our relevant target audience. Focus groups were the most suitable method for our research, as data (here: opinions and statements) is generated by the participants themselves while still being highly comparable because of the consistent input: A stated opinion is instantly reflected by the whole group and counter-arguments (or support for the original statement) are given immediately. This way, a consensus of the group of participants is created and peer-reviewed through communication; whereas in (for example) individual interviews, the respondents would state their opinion without any possible feedback from a peer (as the interviewer should not interfere). Focus groups give the participants the chance to discuss certain aspects controversially, they also get the feeling that their opinion matters (which it of course does); because we worked with teenagers, this was a good way of "warming up" shy participants and therefore reduce fall out [47].

As mentioned before, it is important to raise young women's interest in IT careers at an early age. For our 
focus groups, we therefore looked for female students in German high schools of class 9 and 10, which equals an age of 14 to 16 . At this age, the students are in an early point of their career choice process and are still open to new impulses, which is why it is important to intervene at such an early age [see also e.g. 17]; in our opinion it is also an appropriate way to reduce the aforementioned negative stereotypes regarding IT jobs. Plus, if young students want to choose a career in an IT field, they need to choose the appropriate high-level courses by the age of 16 to 17 (in lines with the German school system). As one of the authors works in a student lab for STEM-subjects, we already had contacts to several of the local secondary schools. Once we had an agreement with teachers, we sent out formal invitations for distribution in the relevant classes. Location-wise, we gave the schools the option to host the focus groups at our student lab or at the school's own computer room, if possible. The focus groups took place in the afternoons, after the regular classes of the students.

We showed the focus groups selected showcase websites. Before, we ranked the websites by evaluating if the respective website serves as a good example for a specific website element. ${ }^{1}$ In terms of the website elements vacancies and account, we did not select additional CACGS, because the showcase websites also partly contained vacancies and accounts. Thus, we were able to ask focus groups for those elements, too, and did not bother the focus groups with too many showcase websites. Finally, we came up with six websites with different dominant career website elements to show them the focus groups.

Originally, we aimed for 6 to 12 students per focus group to make sure each website was analyzed by at least one student. In reality, we had to work with a complete sample of 18 female students from the age of 15 to 16 from three different secondary schools, since many students did not want to take part in the focus groups in the first place, or opted out later. In total, we accumulated approximately 150 minutes of audio material (as we recorded each focus group with the consent of the students and their parents).

We split each of the three focus groups into two parts: during the first 30-40 minutes, we let the students have their own look at the websites, as we wanted to hear their own opinions and not influence them with a special task or agenda. After the explorative part, we started the audio record and began with the interview questions. Besides project-specific

\footnotetext{
${ }^{1}$ We used the following platforms: aubi-plus.de (social media); ausbildung-me.de (mini games); serena.thegoodevil.com (virtual world); portal.berufe-universum.de (online test); whatchado.com/de (videos); planet-beruf.de (information).
}

questions regarding our logo and search techniques regarding job information, we asked each student (or student group) to give the rest of the group a short overview of the website they just tested, and to point out what they liked and did not like as well as possible advantages and disadvantages apart from their own taste. Further, we wanted to know how the students would like to be informed about IT jobs in particular, and how important they consider online tests for finding (possibly) suitable jobs and how accessible they need to be. The interview questions needed to be as open as possible, as we wanted the students to express their own opinions and needed a broad overview of possible preferences.

\subsection{Focus group results}

After transcribing the group interviews from the audio recording, we started coding. We used the Grounded Theory method after Strauss and Corbin, because it allows the researcher to work closely to the material and use direct statements and wording, as opposed to other empirical methods [48].

First, the material was openly coded, which left us with 22 singular codes. In a second step, the axial coding, we clustered these 22 codes into five categories (see Table 1) to structure the material and to assign fitting passages in the material to the separate questions from the interview. As we just wanted to describe what the target audience wishes for in job information websites, we skipped the third step, the selective coding, because we did not need to show connections between the separate findings.

Table 1. Results after axial coding

\begin{tabular}{|l|l|}
\hline \multicolumn{1}{|c|}{ category (How } & \multicolumn{1}{|c|}{ code } \\
\hline $\begin{array}{l}\text { Functionality handling, } \\
\text { should a CACGS work?) }\end{array}$ & $\begin{array}{l}\text { Intuitive nuesentation, } \\
\text { functioning layout, no } \\
\text { pleasant } \\
\text { advertisement }\end{array}$ \\
\hline $\begin{array}{l}\text { Structure (How should } \\
\text { CACGS be build?) }\end{array}$ & $\begin{array}{l}\text { Account login, avatars, } \\
\text { memory function }\end{array}$ \\
\hline $\begin{array}{l}\text { Content/appearance } \\
\text { (What should CACGS } \\
\text { incorporate?) }\end{array}$ & $\begin{array}{l}\text { Blog, activities/ games, } \\
\text { social media, videos, links, } \\
\text { interaction }\end{array}$ \\
\hline $\begin{array}{l}\text { Job information (How } \\
\text { should CACGS depict jobs } \\
\text { and careers?) }\end{array}$ & $\begin{array}{l}\text { Information, online tests, } \\
\text { tips for applications, field } \\
\text { reports, international, filter/ } \\
\text { search bar }\end{array}$ \\
\hline $\begin{array}{l}\text { Addition (How will the } \\
\text { target audience search for } \\
\text { CACGS?) }\end{array}$ & $\begin{array}{l}\text { Search for platforms, } \\
\text { conversations }\end{array}$ \\
\hline
\end{tabular}

Although we hosted three separate focus groups, we found that there was an overall agreement on several points on how to design and use a CACGS.

The main points were the "how and what regarding information": in general, the participants preferred 
homogenous information, like a short portrait or portfolio for each job description presented. That way, users could easily find and compare "hard facts" about several job profiles, one participant stated. Further, interviews or reports of role models from relevant occupational areas were extremely popular, as they offer a realistic insight to the daily tasks of employees. Online tests were quite popular as well, though not as necessary according to the participants. Consensus was that a test might be a useful tool for orientation, but should definitely consider not only skills, but interests and preferences for certain jobs or fields.

When it comes to the structure of a website, the participants preferred a pleasant and clear layout, and liked the idea of a certain color scheme, when used consistently. Pictures, illustrations and even animations were stated as a sort of bonus, "if they aren't too flashy". This goes hand in hand with the wish for a clear and user-friendly design and structure of the whole site. Almost all participants agreed that they do not want to create an account to be able to use the site. Alternatively, there should be an explicit additional benefit from creating an account, but some sort of memory-function would also be imaginable.

Another additional bonus could be the integration of social media, for example the communication with role models or to ask questions. Likewise, this could be achieved with a chat forum or live chat.

Apart from all the consent regarding the major points on how to create a CACGS, there was one factor that was controversially discussed. On the one hand, the use of games and online experiments could be a useful and fun instrument to get a taste of daily tasks and work areas of a certain job, a few participants stated. However, others stated that they did "not want to give the meaningful decision of choosing a career into the hands of a simple game”.

\section{Discussion}

By the means of our findings from literature, the CACGS analysis, and the focus groups, we are finally able to answer our research question. Our CACGS analysis shows that there are mainly career guidance websites for a wide range of occupations and majors that provide basic functional career descriptions, sometimes supported by videos. Although, the findings especially regarding the IT career choice barriers indicate other website elements such as mini games, virtual world and social media as promising for the target group, they are rare. Hence, we suggest that modern (mobile) approaches combined with social and gamified elements can have the potential for a new type of career guidance systems, namely web-based career experience platforms. The experience component is inspired by the construct of user experience (UX) and goes well with our research findings. One popular definition by [28] describes UX as a construct that does not only include task-related utilitarian attributes such as usability, but also hedonic attributes like emotions, personal growth and experiential perspectives. UX also tries to consider the user's past experiences and expectations (e.g. needs, motivations) and the context of the interaction (e.g. social setting, voluntariness of use, etc.). Thus, for us, experience-based career guidance particularly enables stronger user involvement, for example with interaction via simulations of job-related tasks, emotions based on storytelling as well as authentic career presentations and modern mobile web design and usability. We embedded those experience-related aspects in form of Design Recommendations (DRs) presented below. DRs 1 to 4 are each linked to the career choice barriers in Figure 2. DR 5 is a necessary conclusion based on DRs 1 to 4 , as those aspects demand more effort than simply textual database entries of careers as many classic CACGS offer. Thus, the DRs address main issues and implications identified as career choice barriers in section 2 as well as taking into account the findings out of the website analysis and focus groups.

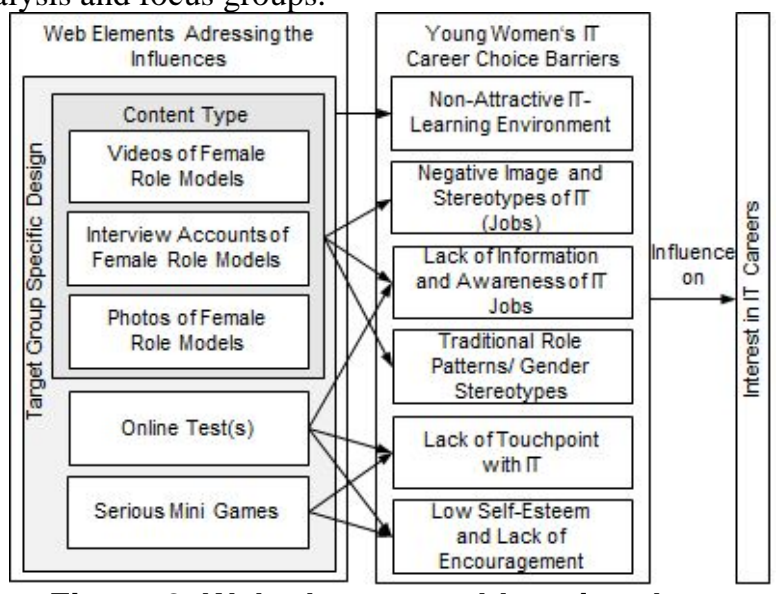

Figure 2. Web elements addressing the barriers of young women's career choice

DR 1: A web-based career experience platform for young women must implement lively authentic content.

Besides functional descriptions of IT careers, lively authentic content in form of videos, interviews and/ or photos of approachable female role models showing their day-to-day IT business could enhance the selfesteem of young women and encourage them. One website ("watchado.de") seemed to be very appealing to the focus groups, on the one hand because of its design, but also because of the underlying storytelling that makes the videos more interesting. As some optional bonus and if the website is actively managed, social interaction functionalities could be implemented 
such as a forum, chat or comments to enable livelier and individual content with role models or peers.

DR 2: A web-based career experience platform for young women must implement serious mini games.

Serious mini games with high regard to real IT tasks could provide hands-on experience and show young women the relevance of IT in real-life applications. In addition, experience-oriented interactive elements and practical activities with realistic and diverse IT challenges, e.g. activities for IT project management or help-desk tasks (and therefore, not only focused on programming games) could address young women`s self-confidence. The focus groups indicated that it is important to put a lot of emphasis on the design so that young women feel taken seriously and the games do not look like a "game" but more like a task.

DR 3: A web-based career experience platform for young women must implement an online test.

Online tests are useful to show young women their strengths and interests, and, thus, improve their selfesteem in terms of IT skills and careers. In addition, they can enhance their awareness of IT jobs as they provide (suitable) career suggestions as a result. However, the tests should be carefully designed so that young women are not rashly limited to specific careers and maybe even careers that do not fit to them at all. At least a test should provide information on how the results are generated. Moreover, a test should not only consider skills, but also interests and preferences for activities.

DR 4: A web-based career experience platform for young women must consider a target group specific design.

Target group specific design aims to use gender specific language and content types by e.g. also addressing female users with their language or showing images of women. An IT career experience website for young women has to put a lot of effort in image changing campaigns of IT, so tech should be seen as cool instead of "nerdy" and "just for men". Young women who see computing as gender neutral and think positive of computing are more likely to have a higher interest in IT. Young women should perceive that working in IT can be very diverse. Thus, career depictions should focus on tasks and attributes instead of job titles. The platform should also highlight social skills that are particularly appealing to young women. By tailoring the website`s design to young women's interests, they can perceive the learning environment as more welcoming. In terms of the overall design, the young generation wants modern, clean, and authentic designs without advertisement. If an account provides no benefit for the target group, they should not be forced to create one.
DR 5: A web-based career experience platform for young women should present selected IT careers.

Presenting a small subset of IT careers comprehensively and with interactive depictions can enhance the understanding for those jobs and relations among each other. It could be further fruitful to show possible career paths between different IT jobs.

\section{Conclusion}

The contribution of this paper consists of design recommendations for a new type of CACGS, i.e. webbased career experience platforms for young women.

To answer our research question, we used a research approach grounded in literature, CACGS analysis, and focus groups. The research combined structural as well as content-based aspects of CACGS. The content-based aspects dealt especially with career choice barriers of young women, whereas the CACGS analysis dealt with the structure and elements of a website. Finally, the focus groups were asked to work with exemplary websites. We synthesized our results out of literature, the website analysis and focus groups to get a comprehensive picture of possible implications.

This paper therefore intents to assist researchers, practitioners, software developer, and policy makers on the design of CACGS. The ultimate aim of this effort is to improve the availability of attractive and valuable information and tools for IT career guidance that are delivered to young women. Another goal is to contribute to an understanding of how technology can be used to enhance career exploration on the internet. Further in-depth research on the usage of games and simulations for career exploration could be fruitful. Moreover, despite a great number of career guidance websites, this type of information system is not well researched (particularly not from an IS perspective) and their characteristics have not been systematically described and analyzed yet. Thus, more research from an IS perspective is necessary.

The study was conducted in Germany. However, as other countries face the same problems, the results may be applicable there, too. This could be validated with a comparing study in the future, taking also into account cultural differences, different levels of security concerns etc.

Paths for solving the current and future female shortage of IT specialists are numerous. One clear approach is to motivate young women to take career paths in these professional fields. However, a webbased approach cannot address all influences, because they are deeply ingrained in the socialization of young women. As these factors are not in our control, they 
were subsequently not part of the study. Nevertheless, a web-based approach can do it`s bit by showing careers and improving career information and exploration. Other initiatives, for example schooling programs, mentoring, or personal career guidance, should further motivate young women and accompany them along their career choice path.

There are also limitations towards our research methods. Firstly, within our research, qualitative methods like focus groups provide an informative value that has to be treated with caution. The sampling and number of participants is not representative for the target group of young women. Yet, the nature of qualitative research does not claim for representativeness like quantitative research. Our primary exploratory goal was to get an idea on how young women evaluate current career guidance websites that we rated as most convincing for a special feature. For instance, one young woman in a focus group was worried about games as they should not be the main factor on which a career decision is based upon. However, this is only a single opinion and should be reflected before generalizing it. Perhaps, already the use of the term "game” did evoke negative connotations. Other research indicates that careerrelated games seem to be a new fruitful approach for carrier guidance and, thus, for further research.

Another restricting aspect towards our research is that the focus groups only give implications based on existing websites, so that the participants draw implications from the experiences they made with the existing websites. Thus, we do not know if they would actually prefer a special feature they currently disliked when it is presented in a different surrounding or implementation (e.g. different design, usability and story). Moreover, the focus groups mentioned additional services like writing an application as helpful. However, this could just have been mentioned because they saw it on several career guidance websites before, and therefore, consider this an inherent element of this type of website. For this reason, it is important to consider their statements critically. A further limitation regarding the CACGS analysis is that it did not consider fee-based websites and it was conducted at a specific time with focus exclusively on Germany. For example, one German career guidance website "blicksta.de" was switched offline by the end of year 2016, so we were no longer able to include it. Other promising and known websites that were cited in literature were neither accessible as well (e.g. fee-based, offline). Moreover, we limited our research on websites and did not analyze native apps for smartphones. Consequently, fruitful avenues for further research on this topic are manifold, especially concerning the use of new technology in form of interactive simulations and games to enhance career guidance services and in terms of how to attract young women with a web-based approach.

\section{References}

[1] Adya, M. and Kaiser, K.M. Early determinants of women in the IT workforce: a model of girls' career choices. Information Technology \& People 18, 3 (2005), 230-259. [2] Ahuja, M.K. Women in the information technology profession: a literature review, synthesis and research agenda. European Journal of Information Systems 11, 1 (2002), 20-34.

[3] Amundson, N., Harris-Bowlsbey, J., and Niles, S. Essential Elements of Career Counseling Processes and Techniques. Pearson, 2008.

[4] Anderson, N., Lankshear, C., Timms, C., and Courtney, L. 'Because it's boring, irrelevant and I don't like computers': Why high school girls avoid professionallyoriented ICT subjects. Computers and Education 50, 4 (2008), 1304-1318.

[5] Angehrn, A. and Maxwell, K. Games in Career Guidance: Effectiveness of Using a SmallWorld Simulation to Develop Social Skills in the Workplace. 2008.

[6] Ashcraft, C., Eger, E., and Friend, M. Girls in IT: The Facts. USA, 2012.

[7] Babin, R., Grant, K.A., and Sawal, L. Identifying Influencers in High School Student ICT Career Choice. Information Systems Education Journal 8, June (2010), 1-18. [8] Bandias, S. and Warne, L. Women in ICT - Retain and Sustain: An Overview of the ACS-W Survey. Proceedings of the 20th Australian Conference on Information Systems (ACIS-20), (2009), 2-17.

[9] Betts, K., Lewis, M., Dressler, A., and L, S. Optimizing learning simulation to support a quinary career development model. Asia-Pacific Journal of Cooperative Education 10, 2 (2009), 99-119.

[10] BITKOM. 51.000 offene Stellen für IT-Spezialisten. 2016.

https://www.bitkom.org/Presse/Presseinformation/51000offene-Stellen-fuer-IT-Spezialisten.html.

[11] Calitz, A.P., Greyling, J.H., and Cullen, M.D.M. ICT Career Track Awareness amongst ICT Graduates.

Proceedings of the 10th South African Institute of Computer Scientists and Information Technologists Conference (SAICSIT-10), (2011), 59-68.

[12] Carter, L. Why Students with an Apparent Aptitude for Computer Science Don't Choose to Major in Computer Science. Proceedings of the 37th SIGCSE Technical Symposium on Computer Science Education (SIGCSE-37), (2006), 27-31.

[13] Clayton, K.L., von Hellens, L.A., and Nielsen, S.H. Gender Stereotypes Prevail in ICT: A Research Review. Public Understanding of Science 23, 2 (2009), 153-158. [14] Copeland, L.Y., Dik, B.J., McLaren, M.R., Onder, C., Wolfson, N.E., and Kraiger, K. Recommendations for using computer-assisted career guidance systems (CACGS) in career counseling practice. Journal of Psychological Issues in Organizational Culture 2, 3 (2011), 86-94.

[15] Craig, A., Fisher, J., and Lang, C. ICT and Girls: The 
Need for a Large Scale Intervention Programme.

Proceedings of the 18th Australasian Conferences on Information Systems (ACIS-18), (2007), 761-769.

[16] Craig, A., Lang, C., and Fisher, J. Twenty Years of Girls into Computing Days: Has It Been Worth the Effort? Journal of Information Technology Education 7, (2008), 339-353.

[17] Dick, T.P. and Rallis, S.F. Factors and Influences on High School Students' Career Choices. Journal for Research in Mathematics Education 22, 4 (1991), 281-292.

[18] Eccles, J. S., Adler, T., Futterman, R., Goff, S. B., Kaczala, C. M., Meece, J. L., \& Midgley, C. Expectancies, Values, and Academic Behaviors. Achievement and Achievement Motivation, (1983).

[19] Eccles, J.S. Studying gender and ethnic differences in participation in math, physical science, and information technology. New Directions for Child and Adolescent Development, 110 (2005), 7-14.

[20] Fisher, J., Lang, C., Craig, A., and Forgasz, H. If Girls Aren't Interested in Computing Can We Change Their Minds? Proceedings of the 23rd European Conference on Information Systems (ECIS-23), (2015), 1-14.

[21] Fowkes, K.M. and McWhirter, E.H. Evaluation of Computer-Assisted Career Guidance in Middle and Secondary Education Settings: Status, Obstacles, and Suggestions. Journal of Career Assessment 15, 3 (2007), 388-400.

[22] Gadassi, R. and Gati, I. The Effect of Gender

Stereotypes on Explicit and Implicit Career Preferences. The Counseling Psychologist 37, 6 (2009), 902-922.

[23] Gati, I. and Asher, I. Prescreening, In-Depth

Exploration, and Choice: From Decision Theory to Career

Counseling Practice. Career Development Quarterly 50, 2 (2001), 140-157.

[24] Gati, I. and Asulin-Peretz, L. Internet-Based Self-Help Career Assessments and Interventions: Challenges and Implications for Evidence-Based Career Counseling. Journal of Career Assessment 19, 3 (2006), 259-273.

[25] Gati, I., Kleiman, T., Saka, N., and Zakai, A. Perceived benefits of using an internet-based interactive career planning system. Journal of Vocational Behavior 62, 2 (2003), 272286.

[26] Groover, T.R. Using Games to Introduce Middle School Girls to Computer Science. Consortium for Computing Sciences in Colleges: Northeastern Conference, (2009), 132138.

[27] Harris-Bowlsbey, J., Dikel, M.F., and Sampson, J.P. The internet: a tool for career planning. National Career

Development, 1998.

[28] Hassenzahl, M. and Tractinsky, N. User experience - a research agenda. Behaviour \& Information Technology 25, 2 (2006), 91-97.

[29] Hayes, E.R. and King, E.M. Not just a dollhouse: what The Sims2 can teach us about women's IT learning. On the Horizon 17, 1 (2009), 60-69.

[30] Heo, M. and Myrick, L.M. The Girls’ Computing Club: Making Positive Changes in Gender Inequity in Computer Science with an Informal, Female Learning Community. International Journal of Information and Communication Technology Education 5, 4 (2009), 44-56.

[31] IfD Allensbach and Vodafone Stiftung. Schule, und dann? (2014).

[32] Katz, M.R. and Shatkin, L. Characteristics of ComputerAssisted Guidance. The Counseling Psychologist 11, 4 (1983), 15-31.

[33] Kelleher, C. and Pausch, R. Lessons learned from designing a programming system to support middle school girls creating animated stories. Proceedings of the IEEE Symposium on Visual Languages and Human-Centric Computing (VL/HCC-2006), (2006), 165-172.

[34] Kettunen, J., Sampson, J.P., and Vuorinen, R. Career practitioners' conceptions of competency for social media in career services. British Journal of Guidance \& Counselling 43, 1 (2015), 43-56.

[35] Kirk, J.J. Web-Assisted Career Counseling. Journal of Employment Counseling 37, 3 (2000), 146-159.

[36] Klawe, M., Whitney, T., and Simard, C. Women in Computing---Take 2. Communications of the ACM 52, 2 (2009), 68-76.

[37] Kompetenzzentrum Technik - Diversity Chancengleichheit. Studienanfängerinnen und Studienanfänger in der Fächergruppe

Ingenieurwissenschaften im Studienjahr 2015. 2016.

[38] Lent, R.W., Brown, S.D., and Hackett, G. Toward a Unifying Social Cognitive Theory of Career and Academic Interest, Choice, and Performance. Journal of Vocational Behavior 45, 1 (1994), 79-122.

[39] Microsoft. Why Europe 's girls aren 't studying STEM. 2017.

[40] Monster Worldwide Deutschland GmbH. Women in IT. 2017.

[41] OECD. Are Students Ready for a Technology-Rich World? What PISA Studies Tell Us. 2005.

[42] OECD. Education at a Glance 2016: OECD Indicators. 2016.

[43] Quaiser-Pohl, C. Woman's choises in STEM - statistical data and theoretical approaches explaining the gender gap. In Women's Choices in Europe - Influence of Gender on Education, Occupational Career and Family Development. Endepohls-Ulpe; C. \& M., New York, 2012, 53-61.

[44] Robinson, N.K.K., Meyer, D., Prince, J.P.P., McLean, C., and Low, R. Mining the Internet for Career Information: A Model Approach for College Students. Journal of Career Assessment 8, 1 (2000), 37-54.

[45] Sampson, J.P. and Osborn, D.S. Using information and communication technology in delivering career interventions. In P.J. Hartung, M.L. Savickas and W.B. Walsh, eds., APA Handbook of Career Intervention. APA, Washington, 2015, 57-70.

[46] Schreiner, C. and Sjøberg, S. The ROSE project: An overview and key findings. 2010.

[47] Schulz, M., Mack, B., and Renn, O. Fokusgruppen in der empirischen Sozialwissenschaft: Von der Konzeption bis zur Auswertung. Springer VS, Wiesbaden, 2012.

[48] Strauss, A., Corbin, J., and Niewiarra, S. Grounded Theory: Grundlagen qualitativer Sozialforschung. Libri, 1996.

[49] Webb, H.C. and Rosson, M.B. Exploring Careers While Learning Alice 3D: A Summer Camp for Middle School Girls. Proceedings of the 42nd ACM Technical Symposium on Computer Science Education (ACM-42), (2011), 377-382. 